\title{
FATIGUE LIFE PREDICTION FOR NI-BASED SUPERALLOY GH4169 CONSIDERING MACHINED SURFACE ROUGHNESS AND RESIDUAL STRESS EFFECTS
}

\author{
Z.R. Wu, S.Q. WAng, X. Yang, L. Pan, Y.D. Song \\ State Key Laboratory of Mechanics and Control of Mechanical Structures, Nanjing University of Aeronautics \\ and Astronautics, Nanjing, China \\ e-mail: zrwu@nuaa.edu.cn
}

\begin{abstract}
Establishing a fatigue life prediction model considering the machined surface state is of great significance to improve fatigue life prediction accuracy. Fatigue tests with different machined surface states of GH4169 alloy were conducted firstly. The influence of surface state parameters on the fatigue life was analyzed. Then, the machined surface stress concentration factor and residual stress were introduced into the fatigue crack initiation and propagation models. Finally, the fatigue life prediction model of GH4169 material considering the surface states was established. The prediction results based on the proposed model are almost within a factor of two scatter band of the test results.
\end{abstract}

Keywords: surface roughness, residual stress, fatigue crack, life prediction, GH4169

\section{Introduction}

GH4169 alloy has excellent mechanical properties, good organizational stability, good creep and fatigue resistance, and can work normally at temperature of $600-1200^{\circ} \mathrm{C}$. It has become the key material for aeroengine hot components and is widely used in manufacturing of blades, turbine disks, combustion chambers, etc. (Ye et al., 2018; Wu et al., 2017). The application of this material in aeroengines needs to consider the requirements of structural strength, creep and fatigue performance. The fatigue performance of the components of aeroengines is directly related to its machined surface integrity. Due to high toughness of GH4169, work hardening can be produced easily. GH4169 material is generally considered as a kind of hard to process material. In the process of machining, tool wear and local high temperature and high pressure make the machined surface easy to produce surface damage and microstructure change, which have a great impact on the fatigue life. The surface quality degradation of GH4169 alloy in the processing process should be considered in the actual components. By choosing an appropriate processing technology, a high surface quality can be obtained, and then the structural strength and fatigue life of the components can be improved. Therefore, it is of great significance to characterize the surface state parameters and introduce typical surface state parameters into the fatigue life prediction model.

In the aspect of analysis of the influence of the machined surface integrity of a nickel-based alloy on the fatigue performance, some scholars have carried out some research work. Ardi et al. (2014) showed that the surface defects, surface roughness and work hardening of nickel-based alloys were the main factors affecting the fatigue performance and failure. Herbert et al. (2014) considered that the residual stress of machined surface was the decisive factor affecting the fatigue performance. Novovic et al. (2004) found that the residual stress had a great influence on the fatigue life when the roughness $R_{a}$ of the machined surface was between 2.5-5 $\mu \mathrm{m}$. Javadi et al. (2018) studied that the surface roughness parameters and residual stress could reduce the 
fatigue life of Inconel 718 alloy. Barrie et al. (2008) studied the influence of surface integrity of shot peened nickel-based alloy Udimet 720 on the low cycle fatigue life, and found that shot peening could reduce the adverse effect of surface inclusions. Tian et al. (2007) studied that the surface hardening and residual compressive stress of milling Hastelloy C-2000 improved the fatigue strength of components. Doremus et al. (2015) studied the effect of different heat treatment Inconel 718 on the low cycle fatigue life, and found that residual compressive stress delayed fatigue crack growth. Chen et al. (2016) studied the influence of the surface integrity of Inconel 718 on the high cycle fatigue life. Microcracks and large residual tensile stress were found on the surface of the workpiece. Sun et al. (2018) showed that appropriate cutting parameters could form high compressive residual stress on the surface of a nickel-based alloy. Suraratchai et al. (2008) introduced the stress concentration factor $K_{t}$ into the Basquin formula and the Paris formula for crack initiation and growth, respectively, to predict the fatigue life. Most of the above researches focusrd on the macroscopic qualitative description of the influence of the surface integrity on the fatigue performance. The research work on the fatigue life model considering surface state parameters is relative less. In this paper, fatigue tests with different machined surface states of GH4169 were conducted. The influence of the surface state parameters on fatigue life was analyzed. On this basis, the surface state parameters were introduced into the fatigue crack initiation and propagation models and, finally, the fatigue life prediction model of GH4169 material considering the surface states was established.

\section{Materials and experimental results}

The material selected in the presented work was Ni-based superalloy GH4169. The main chemical composition of the material is provided in Table 1.

Table 1. The chemical composition of GH4169 [wt\%]

\begin{tabular}{|c|c|c|c|c|c|}
\hline $\mathrm{Nb}$ & $\mathrm{Mo}$ & $\mathrm{Ti}$ & $\mathrm{Cr}$ & $\mathrm{Fe}$ & $\mathrm{Ni}$ \\
\hline \hline 5.67 & 3.84 & 1.40 & 19.14 & 17.20 & 52.76 \\
\hline
\end{tabular}

The following three steps are the heat treatment process for this material: (1) raising the materials temperature to $960^{\circ} \mathrm{C}$ for $1 \mathrm{~h}$, and then air cooling down to room temperature, (2) raising the materials temperature to $720^{\circ} \mathrm{C}$ for $8 \mathrm{~h}$, and then furnace cooling to $620^{\circ} \mathrm{C}$ with the rate $50^{\circ} \mathrm{C} / \mathrm{h},(3)$ holding the materials temperature at $620^{\circ} \mathrm{C}$ for $8 \mathrm{~h}$, and then air cooling to the room temperature. The microstructure of the material is provided in Fig. 1. The second particles at the red arrow in Fig. 1 were discovered around the grain boundaries. The equivalent grain size of GH4169 was defined as the diameter of a circle which has the same area with the selected grain. The statistical distribution histogram of the equivalent grain size is shown in Fig. 2.

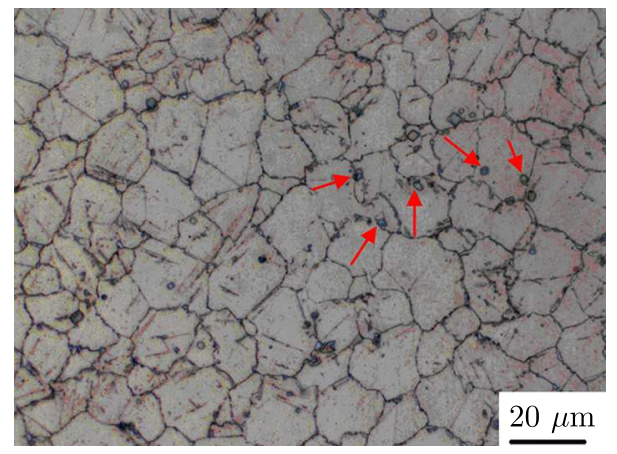

Fig. 1. Typical microstructure of GH4169 (500X) 


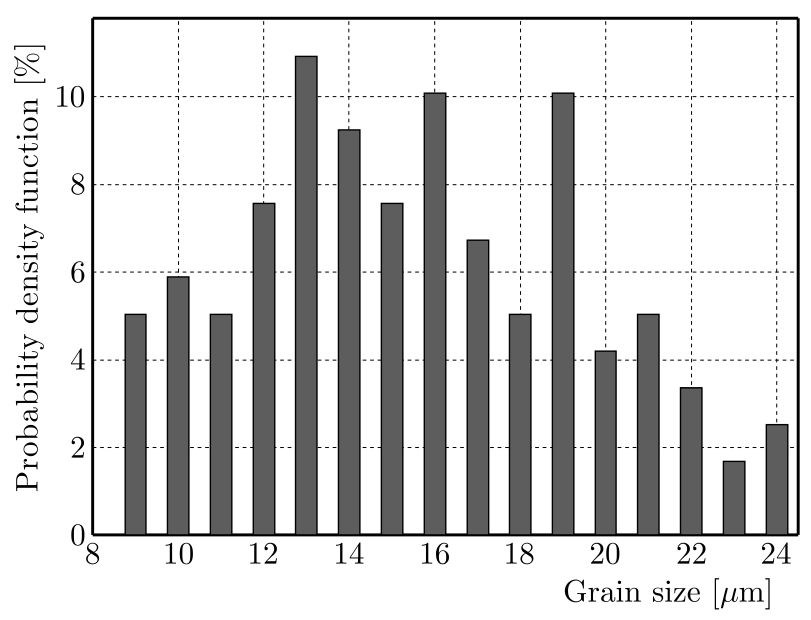

Fig. 2. The distribution of grain size for Ni-based superalloy GH4169

The equivalent grain size is about 9-24 $\mu \mathrm{m}$, and the average equivalent grain size is about $16 \mu \mathrm{m}$. The cylindrical specimen was designed for fatigue tests based on ASTM E606/E606M-12 (ASTM E606, 2012). The detailed configuration and dimensions of the cylindrical specimen are shown in Fig. 3.

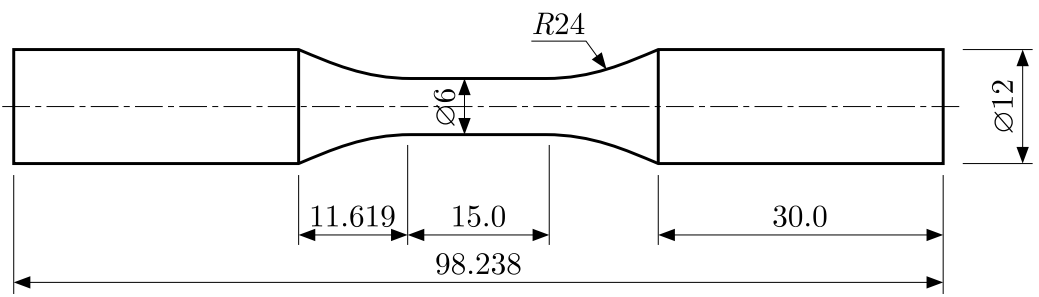

Fig. 3. Cylindrical specimen configuration and dimensions $[\mathrm{mm}]$

The machined surface roughness of the gauge section was measured by Hommel T8000RC roughness profilometer (Fig. 4a), and the machined surface residual stress was measured by the IXRD residual stress analyzer system of Proto Company in Canada (Fig. 4b).

(a)

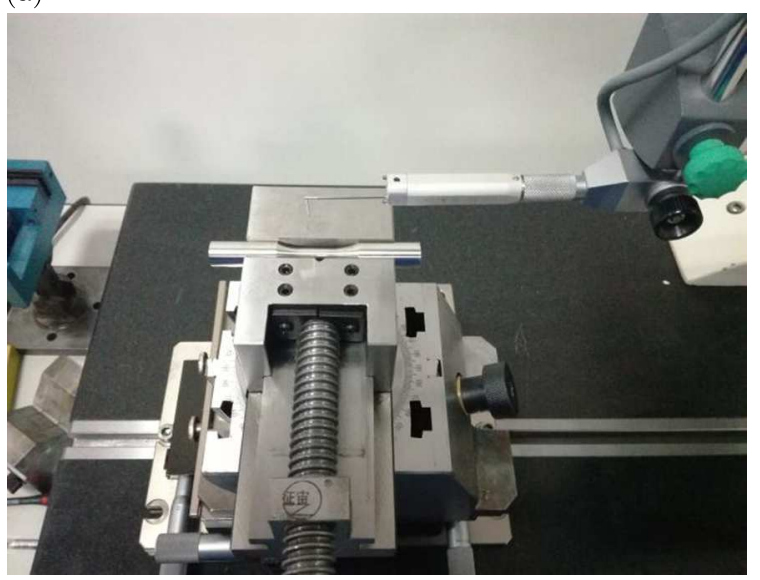

(b)

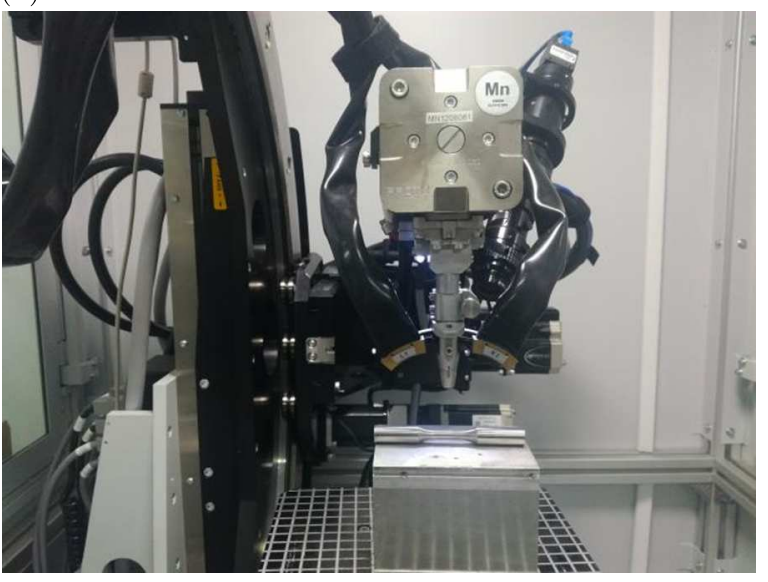

Fig. 4. Measurement of machined surface roughness (a) and the residual stress (b) of the gauge section of the fatigue specimen

Taking the $X$-axis as the surface roughness, $Y$-axis as the residual stress and $Z$-axis as the fatigue life, the relationship between surface state parameters and fatigue life is presented in 
Fig. 5. The surface states of the specimen have a significant effect on the fatigue life under the same stress amplitude. The life of specimens with the average roughness $R_{a}=0.61 \mu \mathrm{m}$, the surface axial residual stress $\sigma_{\text {res }}=-385.6 \mathrm{MPa}$ is the longest, whereas that with the average roughness $R_{a}=1.42 \mu \mathrm{m}$ and $\sigma_{\text {res }}=418.1 \mathrm{MPa}$ is the shortest. The test data show that the specimens with a smaller surface roughness and larger axial compressive residual stress have a longer fatigue life.

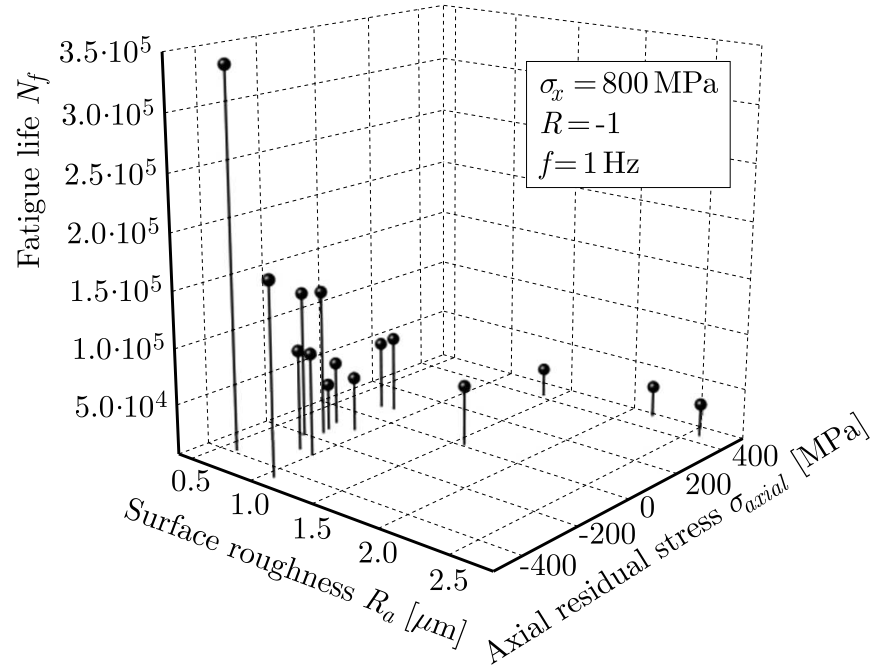

Fig. 5. Relationship between surface state parameters and fatigue life of GH4169 alloy

The axial fatigue tests were conducted with a servo-hydraulic MTS testing system. All fatigue tests were conducted with the nominal maximum stress $\sigma_{\max }=800 \mathrm{MPa}$ and the stress ratio $R=-1$ at room temperature. Sinusoidal waveforms with a frequency of $1 \mathrm{~Hz}$ were chosen as the loading condition. The axial load was taken as the control mode. Figure 6 shows the macroscopic fracture morphology of fatigue specimen No. 7 and No. 12. The stress concentration effect on the machined surface, which forms the fatigue source area on the specimen surface, can be observed. The distance from the fatigue source region to the instantaneous fracture region was defined as the critical crack growth length. The average critical crack growth length is about $4.4968 \mathrm{~mm}$. The results including surface roughness, residual stresses and fatigue tests are summarized in Table 2.

(a)

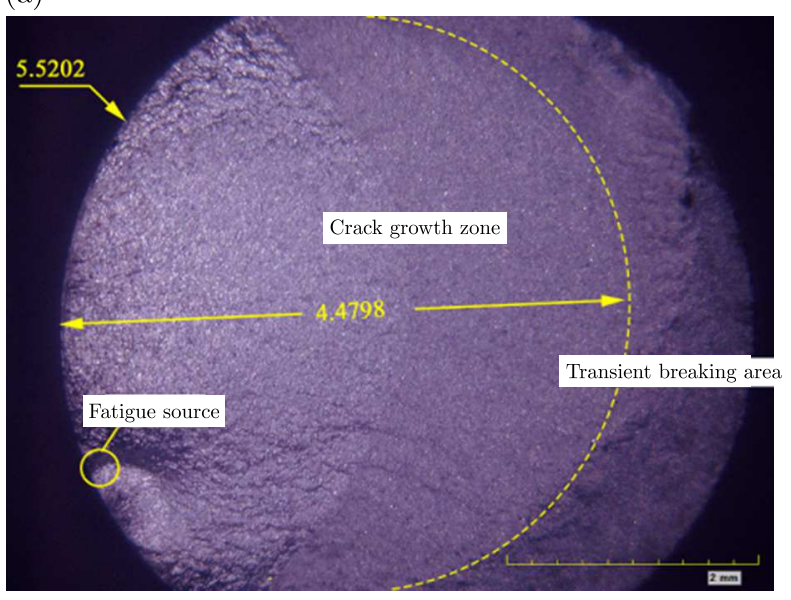

Fig. 6. The macroscopic fracture morphology of fatigue specimen: (a) No. 7, (b) No. 12

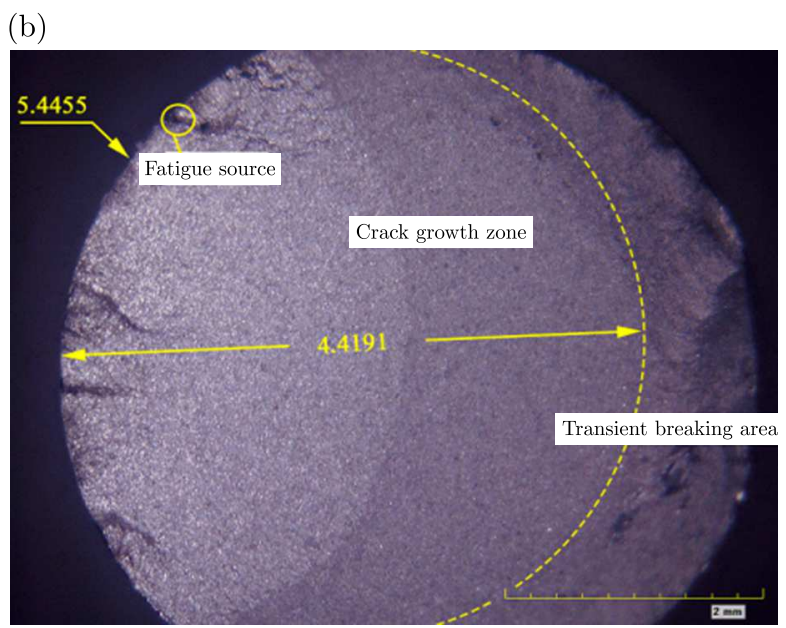


Table 2. Test results including surface roughness, residual stresses and fatigue life

\begin{tabular}{|c|c|c|c|}
\hline $\begin{array}{c}\text { Specimen } \\
\text { number }\end{array}$ & $\begin{array}{c}\text { Average } \\
\text { roughness } \\
R_{a}[\mu \mathrm{m}]\end{array}$ & $\begin{array}{c}\text { Axial } \\
\text { residual stress } \\
\sigma_{\text {res }}[\mathrm{MPa}]\end{array}$ & $\begin{array}{c}\text { Fatigue } \\
\text { life } \\
N_{f}\end{array}$ \\
\hline \hline 1 & 0.73 & -199.2 & 133818 \\
\hline 2 & 0.74 & -87.0 & 60705 \\
\hline 3 & 1.07 & -444.7 & 174583 \\
\hline 4 & 0.80 & -160.5 & 133956 \\
\hline 5 & 0.61 & -385.6 & 337924 \\
\hline 6 & 0.88 & -277.3 & 93776 \\
\hline 7 & 0.85 & 82.1 & 72026 \\
\hline 8 & 0.76 & 75.1 & 65170 \\
\hline 9 & 1.58 & 8.2 & 58887 \\
\hline 10 & 1.42 & 418.1 & 30942 \\
\hline 11 & 2.57 & 443.2 & 34294 \\
\hline 12 & 2.16 & 482.8 & 32802 \\
\hline 13 & 1.00 & -285.3 & 95656 \\
\hline 14 & 0.91 & -93.7 & 53340 \\
\hline 15 & 0.78 & -132.7 & 46497 \\
\hline
\end{tabular}

\section{Theoretical basis}

Under the cyclic loading condition, the total fatigue life of components consists of the crack initiation stage and crack propagation stage as shown in Fig. 7 (Schijve. 2009). The surface integrity parameters have influence both on the fatigue crack initiation and propagation period. The stress concentration factor $K_{t}$ is an important parameter for predicting fatigue crack initiation and growth life. In this Section, the surface integrity parameters were introduced into the calculation process of fatigue crack initiation and crack growth. The fatigue life model of GH4169 alloy considering the surface states was established.

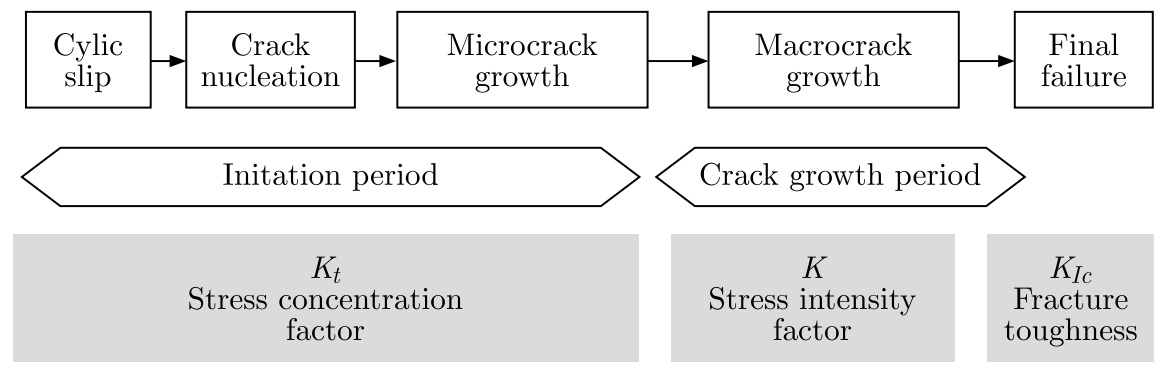

Fig. 7. Fatigue damage evolution process

\subsection{Fatigue crack initiation model considering surface roughness and residual stress effects}

The surface geometry of materials has a direct impact on the fatigue performance of components. The machined surface presents a periodic distribution of peaks and valleys in the microscale. These micro surface geometries create micro notches on the surface. Under a cyclic load, stress concentration at the root of the micro notch on the machined surface promotes the fatigue crack initiation. The machined surface morphology can be approximately equivalent to multiple micro notches with equal depth (Fig. 8). 


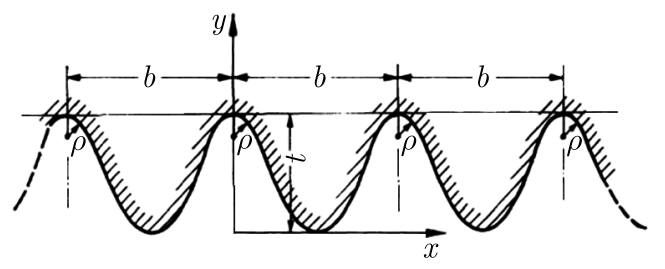

Fig. 8. Multiple micro notches with equal depth

The stress concentration factor $K_{t}$ is usually chosen to describe the effects of geometric discontinuities on strength of engineering components. Therefore, it is reasonable to establish relations between surface topography and fatigue strength of metals in terms of $K_{t}$. From the point of view of simplifying the relationship and facilitating engineering application, successive adjacent notches with the same peak-to-valley height were assumed to describe surface topography. Therefore, the stress concentration factor $K_{t}$ caused by the machined surface can be expressed with Neuber's multiple notches stress concentration calculation method

$$
K_{t}=1+n \sqrt{\gamma \frac{R_{z}}{\rho}}
$$

where $\gamma=b / t, b$ and $t$ are notch spacing and notch depth, respectively. $\rho$ is the radius of curvature at the root of the notch. In the present research, the radius of curvature at the root of a micro notch $\rho$ is defined as the tool nose radius $0.4 \mathrm{~mm}$. $n$ is the coefficient related to the stress state at the notch, where $n=1$ represents the shear stress state and $n=2$ represents the tensile stress state. The coefficient $\gamma$ depends on the ratio of spacing and height of irregularities. For machined surfaces, $\gamma$ can be considered equal to 1 (Zahavi and Torbilo, 1996). $R_{z}$ is 10-point roughness. In the present research, $R_{z}$ is defined as the sum of the average value of the five largest peak heights and the average value of the five largest valley depths in the sampling length. The mathematical expression of $R_{z}$ is as follows

$$
R_{z}=\frac{1}{5}\left(\sum_{i=1}^{5} y_{p i}-\sum_{i=1}^{5} y_{v i}\right)
$$

where $y_{p i}$ and $y_{v i}$ are the peak heights and valley depths, respectively. The $R_{z}$ calculation sketch map is shown in Fig. 9. The stress concentration calculation results are summarized in Table 3.

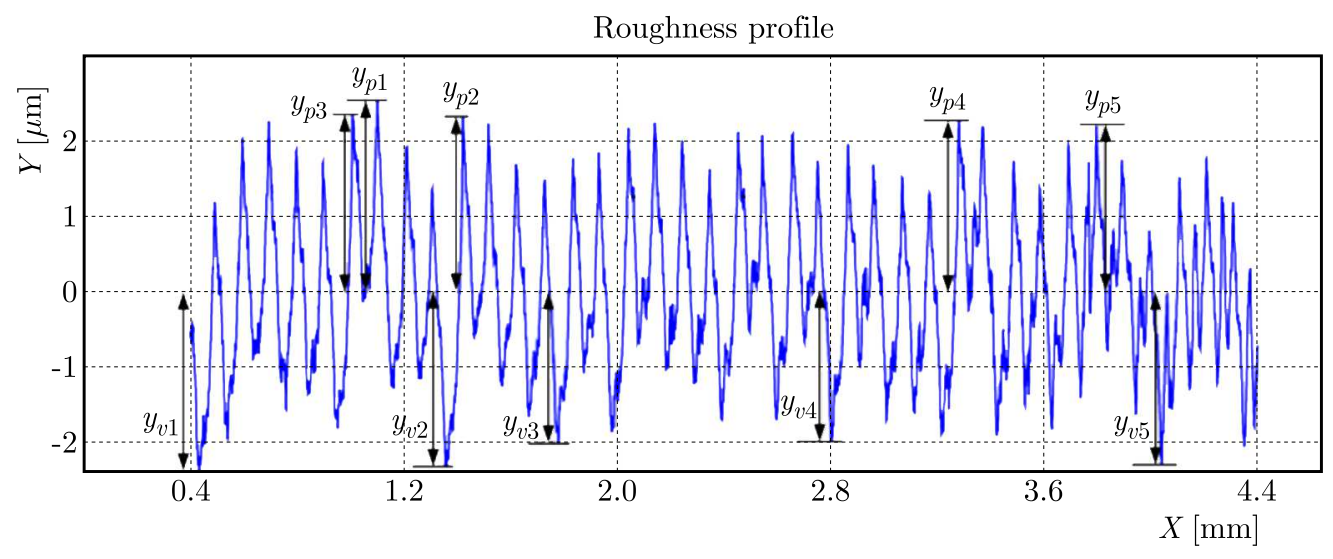

Fig. 9. $R_{z}$ calculation sketch map

The residual stress on the machined surface of components has also an important influence on the fatigue life. A compressive residual stress can prolong the fatigue life and delay the 
Table 3. 10-point roughness and stress concentration factors of fatigue specimens

\begin{tabular}{|c|c|c|}
\hline $\begin{array}{c}\text { Specimen } \\
\text { number }\end{array}$ & $\begin{array}{c}\text { 10-point roughness } \\
R_{z}[\mu \mathrm{m}]\end{array}$ & $\begin{array}{c}\text { Stress concentration } \\
\text { factor } K_{t}\end{array}$ \\
\hline \hline 1 & 4.3602 & 1.2088 \\
\hline 2 & 4.8611 & 1.2208 \\
\hline 3 & 5.9111 & 1.2431 \\
\hline 4 & 4.8938 & 1.2212 \\
\hline 5 & 3.5241 & 1.1877 \\
\hline 6 & 5.5788 & 1.2362 \\
\hline 7 & 4.4426 & 1.2108 \\
\hline 8 & 4.4478 & 1.2109 \\
\hline 9 & 7.8895 & 1.2809 \\
\hline 10 & 7.4692 & 1.2733 \\
\hline 11 & 11.0545 & 1.3325 \\
\hline 12 & 10.3304 & 1.3214 \\
\hline 13 & 6.0828 & 1.2466 \\
\hline 14 & 5.7485 & 1.2398 \\
\hline 15 & 4.3073 & 1.2075 \\
\hline
\end{tabular}

crack initiation, whereas a tensile residual stress can promote the crack initiation. The modified relationship between the stress amplitude and fatigue life considering the effects of surface stress concentration and residual stress is as follows

$$
K_{t} \sigma_{a}=\left(\sigma_{f}^{\prime}-\sigma_{r e s}\right)\left(2 N_{i}\right)^{b}
$$

where $K_{t}$ is the stress concentration factor caused by the machined surface. $\sigma_{a}$ denotes the stress amplitude. $\sigma_{r e s}$ is the residual stress of the machined surface. The residual stress is tensile or compressive, $\sigma_{\text {res }}$ is positive or negative, correspondingly. $N_{i}$ denotes the fatigue crack initiation life. $\sigma_{f}^{\prime}$ and $b$ are the fatigue strength coefficient and fatigue strength index, respectively. For GH4169 material, $\sigma_{f}^{\prime}$ and $b$ are $1815.5 \mathrm{MPa}$ and -0.06 , respectively (Wu etal, 2018). Under the nominal maximum stress $\sigma_{\max }=800 \mathrm{MPa}$ and the stress ratio $R=-1$, the variation curve between the fatigue crack initiation life $N_{i}$ and the machined surface states (stress concentration factor $K_{t}$ and residual stress $\sigma_{\text {res }}$ ) is shown in Fig. 10. Each curve in Fig. 10 represents the predicted crack initiation life under different surface residual stress. With the increase of the surface stress concentration factor, the fatigue crack initiation life decreases significantly. When the stress concentration factor is small, the compressive residual stress on the machined surface can significantly improve the fatigue crack initiation life. With the increase of the surface stress concentration factor, the effect of the compressive residual stress on the fatigue crack initiation life is decreased.

\subsection{Fatigue crack growth model considering surface states}

After initiation of the fatigue crack, there are micro notches on the specimen surface. For a round bar specimen, it can be treated as a semi elliptical surface crack as shown in Fig. 11.

The Paris law based on linear fracture mechanics is always used to describe a stable fatigue crack growth rate

$$
\frac{d a}{d N}=C(\Delta K)^{m}
$$




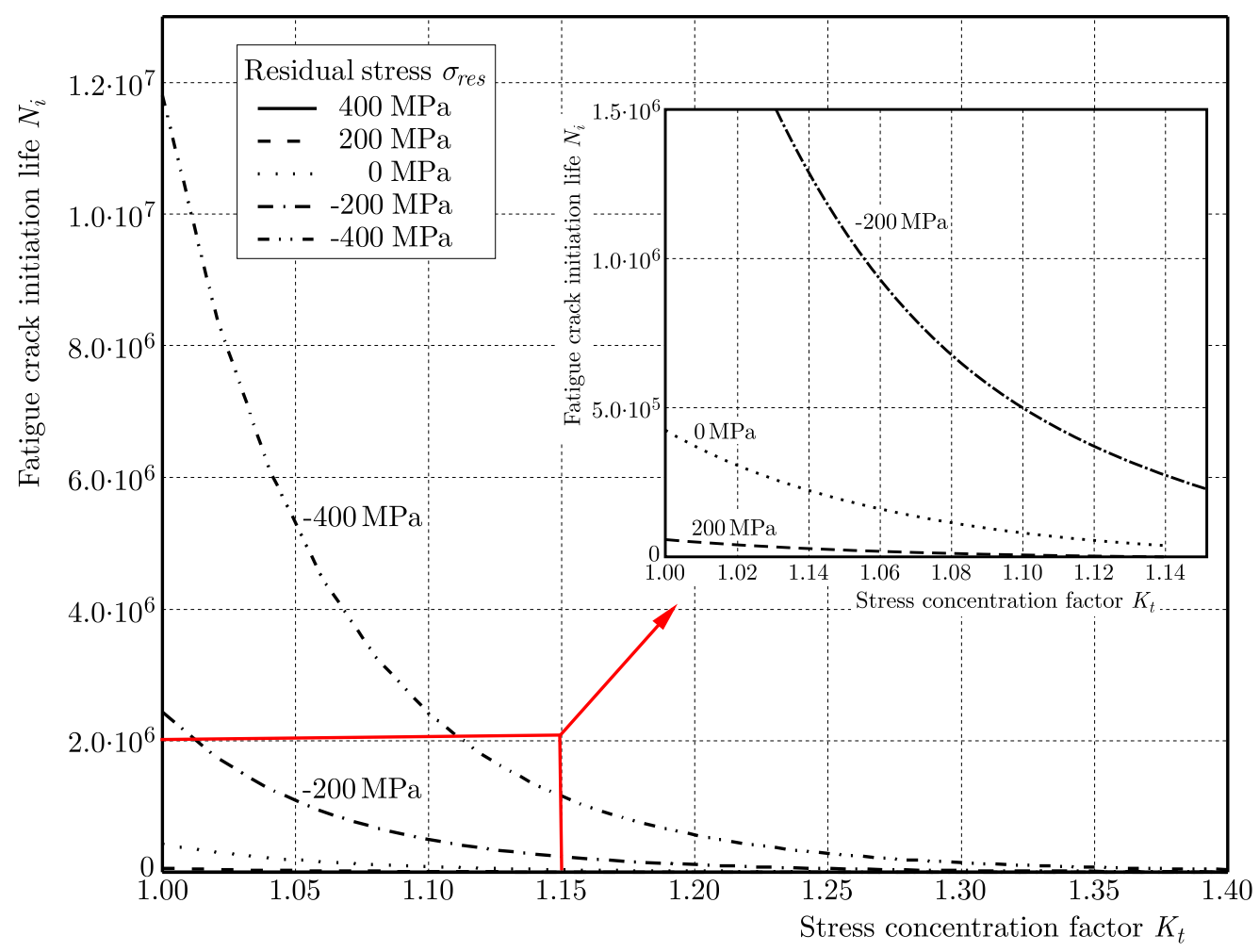

Fig. 10. The variation curve between fatigue the crack initiation life $N_{i}$ and the machined surface states

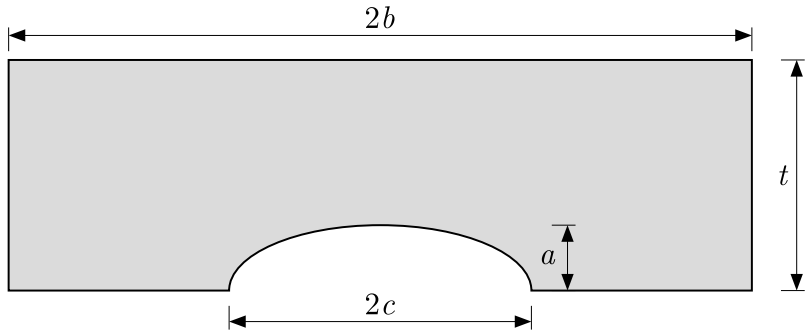

Fig. 11. Sketch map of a semi elliptical surface crack

where $C$ and $m$ are material constants. The stress intensity factor calculation method for a semi elliptical surface crack of the researched test specimens was referred in (Newman and Raju, 1983)

$$
K=\sigma_{t} \sqrt{\frac{\pi a}{Q}} F_{s}\left(\frac{a}{c}, \frac{a}{t}, \frac{c}{b}, \phi\right) \quad F_{s}=\left[M_{1}+M_{2}\left(\frac{a}{t}\right)^{2}+M_{3}\left(\frac{a}{t}\right)^{4}\right] g f_{\phi} f_{w}
$$

where $Q$ and $F_{s}$ denote the crack shape factor and the boundary-correction factor, respectively. The details of calculation methods of $g, f_{\phi}$ and $f_{w}$ can be found in (Newman and Raju, 1983).

Ideally, the fatigue crack can only expand when it is open. The compression load will make the crack closed. The negative part of the stress has no contribution to the crack growth. However, in the actual crack growth process, because of the plastic deformation of the crack surface, in order to meet coordination of deformation, the fatigue crack will close before the complete unloading. Therefore, the crack closure effect must be considered. The effective stress intensity factor range $\Delta k_{\text {eff }}$ was always selected to substitute the stress intensity factor range $\Delta K$ in Eq. (3.4) to consider the crack closure effect. The modified Paris law describing fatigue crack closure effects can be obtained as follows

$$
\frac{d a}{d N}=C\left(\Delta K_{\text {eff }}\right)^{m} \quad \Delta K_{\text {eff }}=K_{\text {max }}-K_{o p}
$$


where $K_{\max }$ and $K_{o p}$ denote the maximum stress intensity factor and the open stress intensity, respectively. The degree of crack closure can be described with the closure factor $U$ which has the following expression

$$
U=\frac{\sigma_{\max }-\sigma_{o p}}{\sigma_{\max }-\sigma_{\min }}=\frac{\Delta K_{\text {eff }}}{\Delta K}
$$

Substituting Eq. (3.6) $)_{1}$ into Eq. (3.5) $)_{1}$, Eq. (3.5) 1 can be expressed as follows

$$
\frac{d a}{d N}=C(U \Delta K)^{m}
$$

where the closure factor $U=0.55+(0.45-\alpha) R+\alpha R^{2}$ (Schijve, 1981). $\alpha$ is the empirical coefficient and the value of $\alpha$ for GH4169 material is determined as 0.15 . The crack growth parameters $C$ and $m$ are obtained from the microcrack growth tests of GH4169 material (Ye et al., 2018). $C$ and $m$ for GH4169 material are $1.18 \cdot 10^{-10}$ and 2.1 , respectively (Ye et al., 2018).

Based on Eq. (3.8), the integral method is used to calculate the crack growth life. The stress concentration factor $K_{t}$ of the machined surface is introduced into the effective stress intensity factor range $\Delta K_{\text {eff. }}$. As the residual stress of the machined surface tends to zero at the depth of $50 \mu \mathrm{m}$ to $100 \mu \mathrm{m}$ from the surface, the influence of residual stress on the crack growth is not considered. Finally, the calculation formula of the crack growth life is obtained as follows

$$
N_{p}=\int_{0}^{N} d N=\int_{a_{0}}^{a_{c}} \frac{d a}{A\left(\Delta K_{\text {eff }}\right)^{m}}=\int_{a_{0}}^{a_{c}} \frac{d a}{A\left(U K_{t} \sigma_{\max } \sqrt{\pi a / Q} F_{s}\right)^{m}}
$$

where $a_{0}$ and $a_{c}$ are the initial crack size and the critical crack size, and $a_{0}$ is defined as the engineering visual crack size of $0.2 \mathrm{~mm}$. Considering the stress concentration effect caused by the machined surface geometry, the stress concentration factor $K_{t}$ is introduced into the calculation of the critical crack size, then $a_{c}$ can be calculated by the following formula

$$
a_{c}=\frac{Q}{\pi}\left(\frac{K_{I C}}{F_{s} K_{t} \sigma_{\max }}\right)^{2}
$$

where $K_{I C}$ is the fracture toughness of mode I crack. At room temperature, the fracture toughness of GH4169 material is $K_{I C}=103.5 \mathrm{MN} / \sqrt{\mathrm{m}^{2}}$. Based on Eq. (3.10), the range of the critical crack size of fatigue specimens with different surface states is in the range of about 3.73-4.69 mm, which is close to the critical crack size observed in the macro morphology of fatigue fracture in Fig. 6. After the initial crack size and critical crack size are determined, the crack growth life of GH4169 material considering the surface state is calculated by Eq. (3.9). The relationship between the crack growth life and the stress concentration factor of the machined surface is plotted in Fig. 12. The crack growth life of GH4169 decreases with the increase of the stress concentration factor. The stress concentration factor $K_{t}$ has an effect on the crack growth of GH4169 alloy.

\subsection{Total fatigue life prediction model for GH4169 alloy}

As mentioned before, the total fatigue life of materials is composed of the crack initiation life and the crack growth life, that is, the total fatigue life $N_{f}$ is

$$
N_{f}=N_{i}+N_{p}
$$

where $N_{i}$ denotes the fatigue initiation life calculated with Eq. (3.3). $N_{p}$ denotes the fatigue growth life calculated with Eq. (3.9). The prediction results are summarized in Table 4. Figure 13 is a comparison diagram of the predicted life and fatigue test life of GH4169 alloy. It can be seen that most of the predicted results are in the double dispersion band. Therefore, the fatigue life prediction model proposed in the present research is feasible to predict the fatigue life of GH4169 samples with different surface states. 


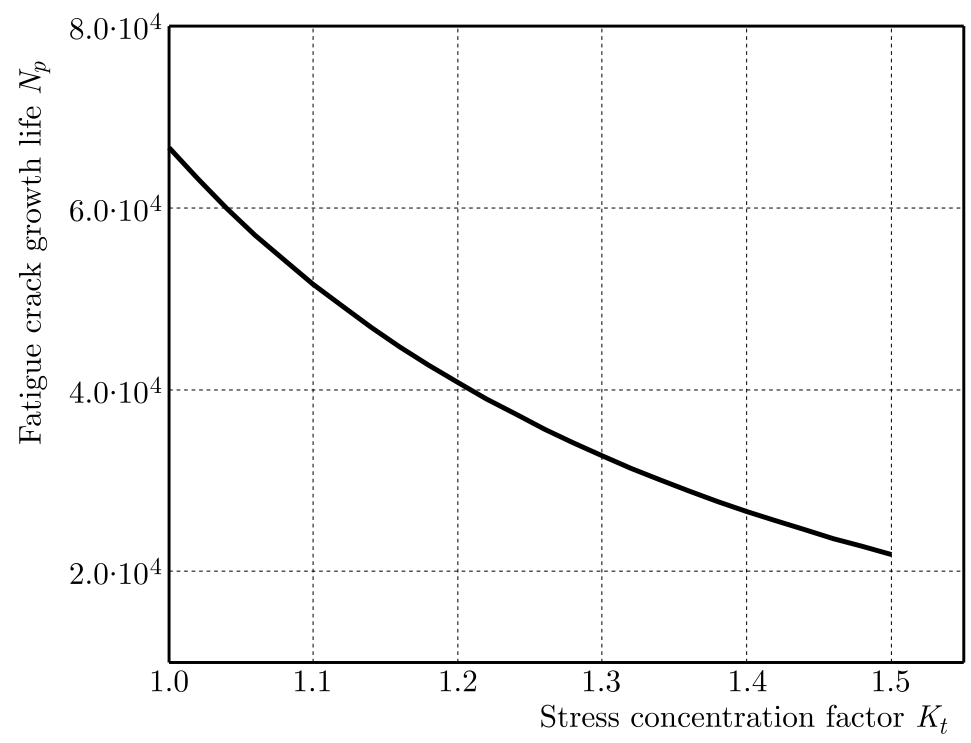

Fig. 12. The relationship between the crack growth life and the stress concentration factor

Table 4. Fatigue life prediction results of GH4169

\begin{tabular}{|c|c|c|}
\hline $\begin{array}{c}\text { Specimen } \\
\text { No. }\end{array}$ & $\begin{array}{c}\text { Experimental life } \\
N_{f, \text { Exp }}\end{array}$ & $\begin{array}{c}\text { Predicted life } \\
N_{f, \text { Pre }}\end{array}$ \\
\hline \hline 1 & 133818 & 142689 \\
\hline 2 & 60705 & 72611 \\
\hline 3 & 174583 & 474859 \\
\hline 4 & 133956 & 101579 \\
\hline 5 & 337924 & 643844 \\
\hline 6 & 93776 & 170884 \\
\hline 7 & 72026 & 47944 \\
\hline 8 & 65170 & 48486 \\
\hline 9 & 58887 & 40485 \\
\hline 10 & 30942 & 34746 \\
\hline 11 & 34294 & 30583 \\
\hline 12 & 32802 & 31290 \\
\hline 13 & 95656 & 160201 \\
\hline 14 & 53340 & 64794 \\
\hline 15 & 46497 & 99833 \\
\hline
\end{tabular}

\section{Conclusions}

In this paper, fatigue tests with different machined surface states of GH4169 were conducted. The influence of surface state parameters on fatigue life was analyzed. The surface state parameters were introduced into the fatigue crack initiation and propagation model and, finally, the fatigue life prediction model of GH4169 material considering the surface state was established. The major conclusions are as follows:

- The fatigue data of GH4169 alloy considering the surface state show that the surface state has a significant effect on the fatigue life. The specimens with a smaller surface roughness and a larger axial compressive residual stress have a longer fatigue life.

- The surface stress concentration factor and residual stress were introduced to establish the crack initiation model. In the crack growth model, the surface stress concentration 


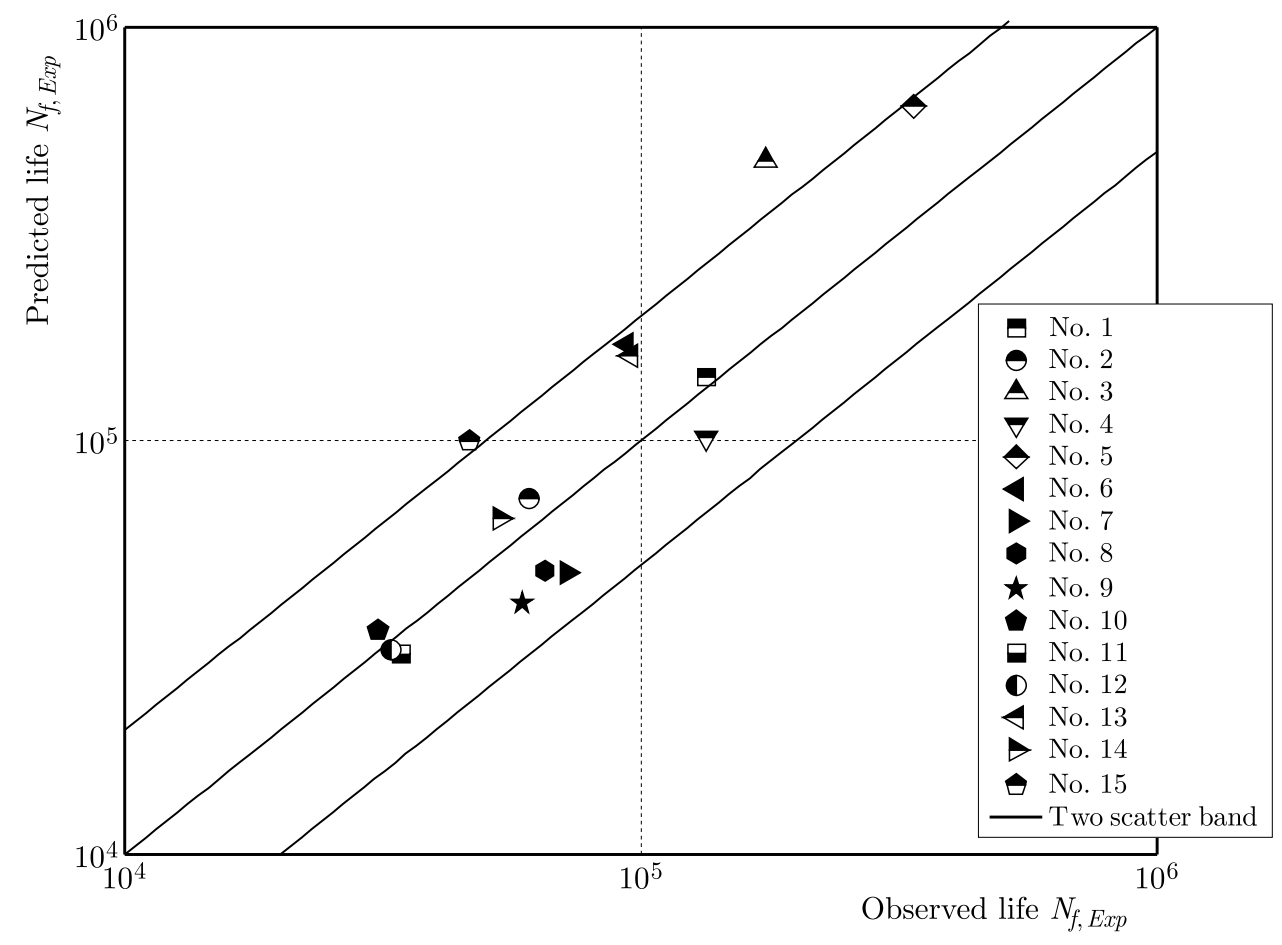

Fig. 13. The comparison of the predicted and experimental lives for GH4169 alloy

factor was introduced to calculate the effective stress intensity factor range $\Delta K_{\text {eff }}$ and the critical crack size $a_{c}$.

- The total fatigue life prediction model composed of crack initiation and propagation models considering the machined surface state was established. Most predicted lives are within a factor of two in the scatter band of the test lives. The results show that the fatigue life prediction model proposed is feasible to predict the fatigue life of GH4169 samples with different surface states.

\section{Acknowledgment}

The present research was supported by the Jiangsu Province Natural Science Foundation of China (No. BK20180440).

\section{References}

1. Ardi D., Li Y.G., Chan K.H.K., Bache M., 2014, Surface roughness, areal topographic measurement, and correlation to LCF behavior in a nickel-based superalloy, Journal of Materials Engineering and Performance, 23, 10, 3657-3665

2. ASTM E606/E606M-12, 2012, Standard text method for strain-controlled fatigue testing

3. Barrie R.L., Gabb T.P., Telesman J., Kantzos P., Prescenzi A., Biles T., Bonacuse P., 2008, Effectiveness of shot peening in suppressing fatigue cracking at non-metallic inclusions in Udimet ${ }^{\circledR}$ 720, Materials Science and Engineering A, 474, 1-2, 71-81

4. Chen Z., Moverare J.J., Peng R.L., Johansson S.A.H., 2016, Surface integrity and fatigue performance of Inconel 718 in wire electrical discharge machining, Procedia CIRP, 45, 307-310

5. Doremus L., Cormier J., Villechaise P., Henaff G., Nadot Y., Pierret S., 2015, Influence of residual stresses on the fatigue crack growth from surface anomalies in a nickel-based superalloy, Materials Science and Engineering A, 644, 234-246 
6. Herbert C., Axinte D.A., Hardy M., Withers P., 2014, Influence of surface anomalies following hole making operations on the fatigue performance for a nickel-based super-alloy, Journal of Manufacturing Science and Engineering, 136, 5, 051016

7. Javadi H., JomaA W., Dalgaard E., Brochu M., Bocher P., 2018, Influence of surface residual stresses on the fatigue life and crack propagation behavior of turned Inconel 718 superalloy, MATEC Web of Conferences, 165, 18004

8. Newman J.C., RaJu I.S., 1983, Stress-intensity factor equations for cracks in three-dimensional finite bodies, Fracture Mechanics: Fourteenth Symposium - Volume I: Theory and Analysis

9. Novovic D., Dewes R.C., Aspinwall D.K., Voice W., Bowen P., 2004, The effect of machined topography and integrity on fatigue life, International Journal of Machine Tools and Manufacture, 44, 2-3, 125-134

10. SchiJve J., 1981, Some formulas for the crack opening stress level, Engineering Fracture Mechanics, 461-465

11. SchiJve J., 2009, Fatigue of Structures and Materials, 2nd ed., Dordrecht: Springer, 621

12. Sun J., Wang T., Su A., Chen W., 2018, Surface integrity and its influence on fatigue life when turning nickel alloy GH4169, Procedia CIRP, 71, 478-483

13. Suraratchai M., Limido J., Mabru C., Chieragatti R., 2008, Modelling the influence of machined surface roughness on the fatigue life of aluminium alloy, International Journal of Fatigue, 30, 12, 2119-2126

14. Tian J.W., Villegas J.C., Yuan W., Fielden D., Shaw L., Liaw P., Klarstrom D., 2007, A study of the effect of nanostructured surface layers on the fatigue behaviors of AC-2000 superalloy, Materials Science and Engineering A, 468, 1, 164-170

15. Wu Z.R., Li X., FAng L., Song Y.D., 2018, Evaluation of multiaxial fatigue life prediction criteria for Ni-based superalloy GH4169, Proceedings of the Institution of Mechanical Engineers Part C: Journal of Mechanical Engineering Science, 232, 10, 1823-1837

16. Wu Z.R., Liu F.L., Li X., FAng L., Song Y.D., 2017, Multistage fatigue modeling of singleedge-notch tension specimens for Ni-based superalloy GH4169, Advances in Mechanical Engineering, 9, 11, 1-11

17. Ye S., Zhang C.-C., Zhang P.Y., Zhang X.-C., Tu S.-T., Wang R.-Z., 2018, Fatigue life prediction of nickel-based GH4169 alloy on the basis of a multi-scale crack propagation approach, Engineering Fracture Mechanics, 199, 29-40

18. Zahavi E., Torbilo V., 1996, Fatigue Design: Life Expectancy of Machine Parts, Boca Raton: CRC Press, $193-194$ 